\title{
Biology and Morphometrics of Tomato Pinworm, Tuta absoluta (Meyrick) on Tomato
}

\author{
V. Abdul Rasheed ${ }^{1 *}$, S.R. Koteswara Rao ${ }^{2}$, T. Ramesh Babu ${ }^{1}$, T. Murali Krishna ${ }^{3}$, \\ B.V. Bhaskara Reddy ${ }^{4}$ and G. Mohan Naidu ${ }^{5}$ \\ ${ }^{1}$ Department of Entomology, S.V. Agricultural College, Tirupati, ANGRAU, India \\ ${ }^{2}$ Adminstrative Office, ANGRAU, Lam, Guntur, India \\ ${ }^{3}$ Krishi Vigyan Kendra (KVK), Kalyandurg, Ananthapuramu, India \\ ${ }^{4}$ IFT, Regional Agricultural Research Station (RARS), Tirupati, India \\ ${ }^{5}$ Department of Statistics and Computer Applications, S.V. Agricultural College, Tirupati, \\ Andhra Pradesh, India \\ *Corresponding author
}

\begin{tabular}{|l|}
\hline Key w o r d s \\
$\begin{array}{l}\text { Tomato pinworm, Tuta } \\
\text { absoluta, Biology, } \\
\text { Morphometrics }\end{array}$ \\
\hline Article Info \\
\hline $\begin{array}{l}\text { Accepted: } \\
\text { 26 October } 2018 \\
\text { Available Online: } \\
\text { 10 November } 2018\end{array}$ \\
\hline
\end{tabular}

\section{A B S T R A C T}

Studies on the biology and morphometrics of tomato pinworm, Tuta absoluta (Meyrick) were conducted at mean temperature $\left(25 \pm 2^{\circ} \mathrm{C}\right)$ and relative humidity $(75 \pm 2 \%)$ in Insectary, Department of Entomology, S.V. Agricultural College, Tirupati on tomato hybrid Sweakar-448. The development period of $T$. absoluta had four stages viz., egg, larva, pupa and adult. The duration of egg, first, second, third and fourth instar larvae was $4.14+0.35,2.08+0.28,2.75+0.65,3.56+0.56$ and $3.86+0.64$ days, respectively. The average length and breadth of egg, first, second, third and fourth instar larvae were $0.48+$ 0.05 and $0.27+0.07 \mathrm{~mm}, 1.51+0.07$ and $0.19+0.02 \mathrm{~mm}, 2.66+0.04$ and $0.39+0.12$ $\mathrm{mm}, 4.22+0.06$ and $0.64+0.03 \mathrm{~mm}$ and $7.59+0.09$ and $1.15+0.04 \mathrm{~mm}$, respectively. The total larval period of T. absoluta ranged from 10 to 14 days with a mean of $12.25+$ 2.13 days. The pupal period lasted for 6 to 9 days with a mean of $7.81+0.75$ days and length and breadth were $4.13+0.24$ and $1.06+0.14 \mathrm{~mm}$, respectively. Adult longevity on an average was $7.45+1.32$ days in case of males whereas $14.75+1.16$ days in case of females. The mean length and breadth of adults were $10.71+0.29$ and $1.69+0.10 \mathrm{~mm}$, respectively. The total development period of $T$. absoluta ranged from 22 to 27 days with a mean of $24.19+1.37$ days. The fecundity of $T$. absoluta ranged from 143 to 218 with a mean of $170.70+19.60$. The pre- oviposition, oviposition and post-oviposition periods of the female were ranged from 1 to 2,4 to 8 and 2 to 4 days with a mean of $1.60+0.50,6.20$ +1.51 and $2.55+0.60$ days, respectively. The hatching per cent of $T$. absoluta eggs ranged from 78.10 to 91.60 with a mean of $86.15+3.48$.

\section{Introduction}

Tomato (Solanum lycopersicum L.) is one of the most widely cultivated and consumed food crops among the vegetables in India. It is consumed as fresh table tomato and as an essential raw material for a variety of food processing industries. Tomato is rich in 
minerals, vitamins and antioxidants that are important to a well-balanced diet. It is also an important dietary component because it contains high levels of lycopene, an antioxidant that reduces the risk associated with several cancers and neurodegenerative diseases. It is used as a salad, paste, peeled tomatoes, diced products, juice, sauces and soups. In India, it is cultivated in an area of 808.54 thousand ha with a production of 19696.92 thousand MT and productivity of 24.36 tonnes ha ${ }^{-1}$ whereas in Andhra Pradesh, it is cultivated in an area of 55.50 thousand ha with a production of 2100.95 thousand MT and productivity of 37.86 tonnes $\mathrm{ha}^{-1}$ during 2016-17 (www.indiastat.com). The major tomato producing states in India are Andhra Pradesh, Karnataka, Orissa, Maharashtra, Madhya Pradesh, West Bengal, Bihar, Gujarat, Uttar Pradesh, Himachal Pradesh, Chhattisgarh, Tamil Nadu, Telangana and Jharkhand. In Andhra Pradesh, the major tomato producing districts are Chittoor, Kadapa, Ananthapuramu, Kurnool, Prakasam and Visakhapatnam.

Tomato production has been fluctuating many biotic and abiotic constraints. Prominent among biotic constraints are pests and diseases which reduce yields and the quality of marketable fruits. Recently, South American tomato leaf miner or pinworm, Tuta absoluta (Meyrick) (Lepidoptera: Gelechiidae), is emerging as major pest and causing extensive damage up to cent per cent yield loss in India particularly under South Indian field conditions. It has been reported from different parts of India throughout the year though the incidence level varies (Sridhar et al., 2014).

In India, T. absoluta was first reported during October, 2014 infesting tomato fields in Pune, Ahmednagar, Dhule, Jalgaon, Nashik and Satara districts of Maharashtra (Shashank et al., 2015). Subsequently, pest was recorded from Karnataka (Sridhar et al., 2014,
Kalleshwaraswamy et al., 2015 and Ballal et al., 2016), Tamil Nadu (Shanmugam et al., 2016 and Ballal et al., 2016), Andhra Pradesh and Telangana (Anitha et al., 2015), New Delhi (Shashank et al., 2016), Gujarat (Ballal et al., 2016), Madhya Pradesh (Swathi et al., 2017), Punjab (Sandeep et al., 2017), Meghalaya (Sankarganesh et al., 2017) and Himachal Pradesh (Sharma and Gavkare, 2017) causing severe damage to tomato in invaded areas in India.

T. absoluta attacks the tomato crop from seedling to harvesting stage. Tomato plants are damaged by feeding on leaves, stems, flower buds and both green and ripe fruits by the invasion of secondary pathogens which enters through the wounds caused by the pest (Shasank et al., 2015). In early infestation, newly emerged neonates penetrate the leaf into the mesophyll layer and feed between the lower and upper surfaces of the leaf to form small and transparent mines. As a result of continuous feeding by the larvae, the irregular mines combine together and eventually form galleries. The mines were filled with black coloured fecal pellets and over time the mined areas turns brown and dryup. In fruits, the larvae tunnel inside and leave only a pin hole visible from outside and make mines just below the surface. More than one hole are seen near to the calyx on fruit. It causes reduction in yield and fruit quality, known to cause 50 to 100 per cent loss under greenhouse and open field conditions.

T. absoluta is a microlepidopteran moth with high reproductive potential. The pest is multivoltine having nearly 10 to 12 generations per year. Females lay eggs singly on the upper and lower surface of the leaf, buds and calyxes of the green fruits. A single female can lay a total of about 260 eggs during its lifetime. Larvae in the initial instars were cream colored, later changes from greenish (second instar) to light pink (fourth 
instar). Larval period is most damaging period which completed within 12 to 15 days (Estay, 2000). Pupation may take place in the soil, on the leaf surface or within the mines, depending on the environmental conditions. Adults are nocturnal and usually hide during the day between leaves. The biological cycle of $T$. absoluta is completed in 29 to 38 days, depending on the environmental conditions. The most important identifying characters are the filiform antennae, silvery-grey scales and characteristic black spots present in anterior wing (Simala et al., 2011). It is a new devastating pest of tomato in India and in Andhra Pradesh, studies on biology of this pest is lacking. Knowledge on biology of this pest is necessary in designing an effective pest management strategy. Keeping the importance of $T$. absoluta in view, its biology was studied under laboratory conditions.

\section{Materials and Methods}

Biology of T. absoluta was studied on tomato hybrid (Sweakar-448) under laboratory conditions at mean temperature $\left(25 \pm 2^{\circ} \mathrm{C}\right)$ and relative humidity $(75 \pm 2 \%)$ in Insectary, Department of Entomology, S.V. Agricultural College, Tirupati.

\section{Mass multiplication of $T$. absoluta under laboratory conditions}

A laboratory population was established with field collected larvae and pupae from tomato growing regions in Chittoor district of Andhra Pradesh which served as the initial culture. This culture was kept in rearing cages $(30 \times 30 \times 30 \mathrm{~cm})$ in which tomato seedlings and foliage were placed as a source of food. When the leaves were fully mined fresh tomato leaves were provided to the larvae until pupation. After pupation, the pupae were kept in plastic jars for adult emergence. The newly emerged moths were enclosed in separate cages for mating. Twenty days old tomato seedlings were provided for oviposition. Fresh seedlings were provided for every $24 \mathrm{hrs}$ until the completion of oviposition by the female adults. The cotton wads soaked in honey $(0.5 \%)$ fortified with vitamin $\mathrm{E}$ were provided as food for the moths. The plant parts containing the freshly laid eggs were removed daily and kept for hatching. Newly hatched larvae were transferred to tomato leaves.

Daily fresh leaves were provided until pupation. Rearing was continued till the emergence of the adults. This culture was used for studying the biology of the T. absoluta.

\section{Biology of $T$. absoluta under laboratory conditions}

To study the biology of T. absoluta one pair (male and female) were released on to twenty days old tomato seedlings (Sweakar-448) kept in separate cages for oviposition. Twenty four hours after release, the seedlings with fresh eggs were taken and observed under trinocular stereo zoom microscope. Then freshly laid thirty eggs were placed into petri plates $(9 \mathrm{~cm}$ diameter). Each egg was placed in a separate petri plate. Eggs were examined daily for hatching. Fresh foliage was provided for newly emerged larvae and observed daily through pupation and adult emergence. Individual insects were observed daily for their development and survival. Observations on hatching rate (\%), egg, larval, pupal period, adult longevity and total life cycle were recorded (Nayana and Kalleshwaraswamy, 2015). Only individuals that survived to the adult stage were included in the analysis. This experiment was replicated twice. Fecundity, pre-oviposition, oviposition and postoviposition periods were also recorded. Egg, larval instars, pupae and adults were observed by using stereo zoom trinocular microscope with Dewinter Calipers Pro Version 4.6 software at Department of Entomology, S.V. Agricultural College, Tirupati. 


\section{Incubation period}

Egg period was recorded as the duration of time taken from egg laying to hatching which was recognized by hatching of the larva through the egg chorion.

\section{Larval period}

The duration of larval period was recorded as the number of days taken from hatching of egg to the pupation of last instar larva.

To determine the number of larval instars and the duration of each instar, leaves with eggs laid on the same day were segregated and placed in petri plates $(9 \mathrm{~cm}$ diameter).

From these, leaves with the eggs hatching on the same day were separated and pooled.

Each day leaves were carefully dissected and the stage (instar) of larva present inside the leaf mine was determined based on the width of head capsule. The process was continued till pupal stages.

\section{Pupal period}

Pupal period was recorded from the formation of pupa till the emergence of adult.

\section{Total development period}

Total development period from egg to adult was computed by counting the data obtained from observations and the data regarding duration of various stages of the pest were presented.

\section{Adult longevity}

The life span of adults was recorded by enclosing twenty male and twenty female adults in separate test tubes with 10 per cent honey solution.

\section{Pre-oviposition, oviposition and post- oviposition periods}

Twenty pairs (one male and one female) were taken and kept separately in different cages along with the tomato seedlings to know the pre-oviposition, oviposition and post oviposition periods.

\section{Fecundity}

Fecundity was recorded for twenty females by counting the number of eggs laid during the oviposition period for each female.

\section{Hatching rate (\%)}

Number of eggs hatched out of total number of eggs was recorded at regular intervals during the oviposition period.

\section{Morphometrics of T. absoluta}

Morphometrics of egg, larva (each instar), pupa, adult and head capsule were measured by using stereo zoom trinocular microscope with Dewinter Calipers Pro Version 4.6 software at Department of Entomology, S.V. Agricultural College, Tirupati and expressed in millimetres $(\mathrm{mm})$.

\section{Results and Discussion}

The biology and morphometrics of T. absoluta on tomato (Sweakar-448) was studied under laboratory conditions at mean temperature $\left(25 \pm 2^{\circ} \mathrm{C}\right)$ and relative humidity $(75 \pm 2 \%)$ in Insectary, Department of Entomology, S.V. Agricultural College, Tirupati. The results are presented in Tables 1 to 4 . The life cycle of $T$. absoluta consists of four developmental stages viz., egg, larva, pupa and adult. Eggs laid singly on the upper and lower surfaces of the leaves, buds, stems and calyx. A brief description of each development stage is illustrated hereunder. 


\section{Incubation period}

Eggs were small, oval or oblong, microscopic, creamy white in colour when laid and later turned to yellow and finally to black before hatching. Incubation period ranged from 4 to 5 days with a mean of $4.14+0.35$ days (Table 1). The present results are comparable with the findings of Erdogan and Babaroglu (2014) and Manoj et al., (2017) who reported the egg period of T. absoluta as 4.10 days and $4.08 \pm$ 0.55 days, respectively. Similarly, Nayana and Kalleshwaraswamy (2015) and Sridhar et al., (2015) also reported that the incubation period of $T$. absoluta lasted for $3.90+0.91$ and 3.75 \pm 1.11 days, respectively. The mean length and breadth of eggs were $0.48+0.05$ and $0.27+$ $0.07 \mathrm{~mm}$, respectively (Table 3 ).

\section{Larva}

During the present study, larva undergone three moults and four larval instars were recorded. Based on width of the head capsule and exuviae in each moulting the instars were recognised.

\section{First instar larva}

First instar larva was white or cream colour with prominent black head. It was very sensitive and immediately after hatching mined within the leaves. The duration of first instar larva was 2-3 days with a mean of 2.08 +0.28 days (Table 1). The mean length and breadth of first instar larva was $1.51+0.07$ and $0.19+0.02 \mathrm{~mm}$, respectively (Table 3 ).

The head capsule width of first instar larva ranged from 0.16 to $0.22 \mathrm{~mm}$ with a mean of $0.18+0.02 \mathrm{~mm}$ (Table 4).

\section{Second instar larva}

Second instar larva was cream colour with black head. The duration of second instar larva ranged from 2 to 4 days with a mean of $2.75+$
0.65 days (Table 1). The mean length and breadth of second instar larva were $2.66+$ 0.04 and $0.39+0.12 \mathrm{~mm}$, respectively (Table $3)$. The head capsule width of second instar larva ranged from 0.24 to $0.35 \mathrm{~mm}$ with a mean of $0.30+0.03 \mathrm{~mm}$ (Table 4).

\section{Third instar larva}

Third instar larva was greenish in colour with dark brown head. At this instar the larva was more active, fed more and size increased gradually than the first and second instars. The duration of third instar larva ranged from 3 to 5 days with a mean of $3.56+0.56$ days (Table 1). The mean length and breadth of third instar larva was $4.22+0.06$ and $0.64+0.03 \mathrm{~mm}$, respectively (Table 3 ). The head capsule width of third instar larva ranged from 0.35 to 0.45 $\mathrm{mm}$ with a mean of $0.38+0.03 \mathrm{~mm}$ (Table 4).

\section{Fourth instar larva}

Fourth instar larva was greenish to pink colour with dark brown head. At this instar the larva fed more voraciously. It was easily recognised by the presence of pinkish bands on dorsal surface of larva. The duration of fourth instar larva ranged from 3 to 5 days with a mean of $3.86+0.64$ days (Table 1). The mean length and breadth of fourth instar larva was $7.59+$ 0.09 and $1.15+0.04 \mathrm{~mm}$, respectively (Table 3). The head capsule width of fourth instar larva ranged from 0.53 to $0.63 \mathrm{~mm}$ with a mean of $0.58+0.04 \mathrm{~mm}$ (Table 4 ).

The total larval period of $T$. absoluta ranged from 10 to 14 days with a mean of $12.25+$ 2.13 days (Table 1). These results are close in agreement with the findings of Nayana and Kalleshwaraswamy (2015) and Pereyra and Sanchez (2006) who reported that, the larval period of T. absoluta was $11.80+1.25$ and 12.14 days, respectively. Similarly, Shehata $e t$ al., (2016) also recorded T. absoluta larval duration as $11.7 \pm 0.47$ days. 
Table.1 Duration of different development stages of T. absoluta on tomato

\begin{tabular}{|c|c|}
\hline Stage of the pest & \multicolumn{2}{|c|}{$\begin{array}{c}\text { Development period (Days) } \\
\text { Mean } \pm \text { SD }\end{array}$} \\
\hline Egg & $4.14 \pm 0.35$ \\
\hline & Larva \\
\hline $1^{\text {st }}$ instar & $2.08 \pm 0.28$ \\
\hline $2^{\text {nd }}$ instar & $2.75 \pm 0.65$ \\
\hline $3^{\text {rd }}$ instar & $3.56 \pm 0.56$ \\
\hline $4^{\text {th }}$ instar & $3.86 \pm 0.64$ \\
\hline Total larval period & $12.25 \pm 2.13$ \\
\hline Pupa & $7.81 \pm 0.75$ \\
\hline Total development period & $24.19 \pm 1.37$ \\
\hline
\end{tabular}

Table.2 Pre-oviposition period, oviposition period, post oviposition period, fecundity, hatching (\%), adult longevity of male and female of T. absoluta on tomato

\begin{tabular}{|c|}
\hline Parameter \\
\hline Pre-oviposition period (Days) \\
\hline Oviposition period (Days) \\
\hline Post-oviposition period (Days) \\
\hline Fecundity \\
\hline Hatching (\%) \\
\hline Male adult longevity (Days) \\
\hline Female adult longevity (Days) \\
\hline
\end{tabular}

\begin{tabular}{|c|}
\hline Mean + SD \\
\hline $1.60 \pm 0.50$ \\
\hline $6.20 \pm 1.51$ \\
\hline $2.55 \pm 0.60$ \\
\hline $170.70 \pm 19.60$ \\
\hline $86.15 \pm 3.48$ \\
\hline $7.45 \pm 1.32$ \\
\hline $14.75 \pm 1.16$ \\
\hline
\end{tabular}

Table.3 Morphometric dimensions of different development stages of T. absoluta on tomato

\begin{tabular}{|c|c|c|}
\hline $\begin{array}{c}\text { Development } \\
\text { Stage }\end{array}$ & \multicolumn{2}{|c|}{ Mean + SD } \\
\hline Egg & $0.48 \pm 0.05$ & Breadth $(\mathbf{m m})$ \\
\hline & Larva & $0.27 \pm 0.07$ \\
\hline $\mathbf{1}^{\text {st }}$ instar & $1.51 \pm 0.07$ & $0.19 \pm 0.02$ \\
\hline $2^{\text {nd }}$ instar & $2.66 \pm 0.04$ & $0.39 \pm 0.12$ \\
\hline $3^{\text {rd }}$ instar & $4.22 \pm 0.06$ & $0.64 \pm 0.03$ \\
\hline $4^{\text {th }}$ instar & $7.59 \pm 0.09$ & $1.15 \pm 0.04$ \\
\hline Pupa & $4.13 \pm 0.24$ & $1.06 \pm 0.14$ \\
\hline Adult & $10.71 \pm 0.29$ & $1.69 \pm 0.10$ \\
\hline
\end{tabular}

Table.4 Head capsule width of different larval stages of T. absoluta on tomato

\begin{tabular}{|c|c|c|c|c|}
\hline \multirow{2}{*}{ Host } & \multicolumn{4}{|c|}{ Head capsule width (mm) } \\
\cline { 2 - 5 } & I instar & II instar & III instar & IV instar \\
\hline Tomato & $0.18 \pm 0.02$ & $0.30 \pm 0.03$ & $0.38 \pm 0.03$ & $0.58 \pm 0.04$ \\
\hline
\end{tabular}


Polat et al., (2016) who reported that the larval period as 12.82 to 26.7 days. Torres et al., (2001) observed that larval period of $T$. absoluta as 12 to 16 days at $27^{\circ} \mathrm{C}$.

\section{Pupal period}

The pupa was greenish yellow initially and later turned to brown. Pupation took in folded leaves or filter paper in laboratory. Male and female pupa was differentiated based on the size. Female pupa was larger than the male. Wing case is nearer to posterior abdominal segment in case of males whereas in females it is away to posterior abdominal segment. Pupal period ranged from 6 to 9 days with a mean of $7.81+0.75$ days (Table 1 ). The present results are in close agreement with the findings of Torres et al., (2001) who reported pupal period of T. absoluta lasts for 7 to 9 days at $27^{\circ} \mathrm{C}$. Similar results were obtained by Bajracharya and Bhat (2018) who recorded the average pupal period of $T$. absoluta as 7.11 days. Ballal et al., (2016) and Polat et $a l .$, (2016) also reported the pupal period of $T$. absoluta lasts for 10 and 7.52 to 20.62 days, respectively. The mean length and breadth of pupa was $4.13+0.24$ and $1.06+0.14 \mathrm{~mm}$, respectively (Table 3 ).

\section{Total development period}

The total development period of $T$. absoluta ranged from 22 to 27 days with a mean of $24.19+1.37$ days on tomato (Table 1 ). The results of present investigations are supported with the findings of Ballal et al., (2016) who reported that $T$. absoluta life cycle was 21 to 23 days on tomato. Similar results were also reported by Barrientos et al., (1998) and Desneux et al., (2010) who recorded the duration of the life cycle of $T$. absoluta on tomato as 20 to 27 and 26 to 31days, respectively. Head capsule size and instar statistics are necessary to understand basic phenomena associated with larval stage of insect. The effect of any insecticide varies according to instar. This fundamental entomological information is important for proper timing of insecticides application as it depends upon the dominance of particular larval stage in field conditions. Instar information is also necessary in proper application of entomopathogens for effective management of insect pest. These findings on biology and morphometrics will help in understanding the development of T. absoluta and formulation of effective management strategy against it.

\section{Adult longevity}

Adult moths were small, nocturnal, brown to silver scales with black spots on the forewings. The antennae are filiform and the wings are fringed. Males are slightly darker and smaller than females. Females are light in colour and larger than males. The abdomen of the female moths is wider compared to narrower and pointed abdomen of males. The longevity of the male ranged from 5 to 9 days with a mean of $7.45+1.32$ days where as female longevity ranged from 12 to 16 days with a mean of $14.75+1.16$ days (Table 2 ). Longevity of the females was more than males. Manoj et al., (2017) reported $7.50 \pm$ 1.20 days as longevity of adult male and $15.01 \pm 1.47$ days for female, which was similar to present findings. In contrary to present findings, Polat et al., (2016) reported that the longevity of males and females were 3.37 to 6.14 and 7.7 to 9.75 days, respectively. The mean length and breadth of adults were $10.71+0.29$ and $1.69+0.10 \mathrm{~mm}$, respectively.

\section{Fecundity}

The number of eggs laid per female ranged from 143 to 218 with a mean of $170.70+$ 19.60 on tomato (Table 2). The present results are comparable with the findings of Manoj et 
al., (2017) who reported that the fecundity varied from $165.05 \pm 6.22$ eggs per female. Similarly, Salama et al., (2014) also recorded the fecundity of T. absoluta varied from $162 \pm$ 30.94 eggs per female.

\section{Pre-oviposition, oviposition and post- oviposition periods}

The pre- oviposition, oviposition and postoviposition periods of the female were ranged from 1 to 2,4 to 8 and 2 to 4 days with a mean of $1.60+0.50,6.20+1.51$ and $2.55+$ 0.60 days, respectively (Table 2 ). The results of present finding are in close agreement with the findings of Erdogan and Babaroglu (2014) who reported that the pre oviposition, oviposition periods were 1.28 and 7.88 days, respectively.

\section{Hatching rate $(\%)$}

The hatching per cent of $T$. absoluta eggs ranged from 78.10 to 91.60 with a mean of $86.15+3.48$ (Table 2).

\section{References}

Anitha, K. D., Anitha, A., Anitha, A., Lakshmi, B.K.M., Vennila, S and Rao, N.H.P. 2015. New record of leaf miner, Tuta absoluta (Meyrick) in tomato. Insect Environment. 20(4): 136-137.

Bajracharya, A.S.R and Bhat, B.2018. Life cycle of South American tomato leaf miner, Tuta absoluta (Meyrick, 1917) in Nepal. Journal of Entomology and Zoology Studies. 6(1): 287-290.

Bajracharya, A.S.R., Mainali, R.P., Bhat, B., Bista, S., Shashank, P.R and Meshram, N.M. 2016. The first record of South American tomato leaf miner, Tuta absoluta (Meyrick, 1917) (Lepidoptera: Gelechiidae) in Nepal. Journal of Entomology and Zoology Studies. 4(4): 1359-1363.
Balaji, D.R., Jeyarani, Ramaraju, S.K., Mohan, S and Shanmugam, P.S. 2018. Occurrence of South American tomato pinworm, Tuta absoluta (Meyrick) (Lepidoptera: Gelechiidae): An invasive pest in Tamil Nadu, India. Journal of Entomology and Zoology Studies. 6(2): 657-662.

Ballal, C.R., Ankita, G., Mohan, M., Lalitha, $\mathrm{Y}$ and Abraham, V. 2016. The new invasive pest Tuta absoluta (Meyrick) (Lepidoptera: Gelechiidae) in India and its natural enemies along with evaluation of Trichogrammatids for its biological control. Current Science. 110:1-6

Barrientos, Z.R.; Apablaza, H.J.; Norero, S.A and Estay, P.P. 1998. Threshold temperature and thermal constant for development of the South American tomato moth, Tuta absoluta (Lepidoptera: Gelechiidae). Ciencia Investigacion Agraria. 25: 133-137.

Desneux, N., Wajnberg, E., Wyckhuys, K.A.G., Burgio, G., Arpaia, S., Narvaez-Vasquez, C.A., Gonza lezcabrera,J., Catala n Ruescas, D., Tabone, E., Frandon, J., Pizzol, J., Poncet, C., Cabello, T and Urbaneja, A. 2010. Biological invasion of European tomato crops by Tuta absoluta: ecology, geographical expansion and prospectus for biological control. Journal of Pest Science.83: 1-19.

EPPO.2005. Datasheet of Tuta absoluta. OEPP/EPPO Bulletin 35: 434-435

Erdogan, P and Babaroglu, N. E. 2014. Life table of the tomato leaf Miner, Tuta absoluta (Meyrick) (Lepidoptera: Gelechiidae). Journal of Agricultural Faculty of Gaziosmanpasa University. 31(2): 80-89.

Estay, P. 2000. Tomato moth Tuta absoluta (Meyrick). Institute of Agricultural Research, Regional Research Center La 
Platina, Ministry of Agriculture Santiago Chile.

Hossain, M. S., Mian, M.Y and Muniappan, R. 2016. First record of Tuta absoluta (Lepidoptera: Gelechiidae) from Bangladesh. Journal of Agricultural and Urban Entomology. 32:101-105.

Kalleshwaraswamy, M.C., Murthy, S., Viraktamath, C.A and Kumar, N.K. 2015. Occurrence of Tuta absoluta (Lepidoptera: Gelechiidae) in the Malnad and Hyderabad-Karnataka Regions of Karnataka, India. Florida Entomological Society. 98(3):970-971.

Manoj, K., Arun, K.H., Bheemanna, M., Vijay, K.G., Basave, G and Ravindra, G.P. 2017. Biology of Tomato Leaf Miner, Tuta absoluta (Meyrick) (Lepidoptera: Gelechiidae) under laboratory conditions. Journal of Experimental Zoology, India. 20(1):373-375.

Nayana, B. P and Kalleshwaraswamy, C. M. 2015. Biology and external morphology of invasive tomato leaf miner, Tuta absoluta (Meyrick) (Lepidoptera: Gelechiidae).

Pest Management in Horticultural Ecosystems. 21(2): 169-174

NICRA team of tomato pest surveillance. 2012. Manual for tomato pest surveillance. Jointly published by National Centre for Integrated Pest Management, New Delhi; Central Institute for Dryland Agriculture, Hyderabad; Indian Institute of Horticultural Research, Bengaluru and Indian Institute of Vegetable Research, Varanasi.39.

Pereyra, C.P and Sánchez. N.E. 2006. Effect of two solanaceous plants on developmental and population parameters of the tomato leaf miner, Tuta absoluta (Meyrick) (Lepidoptera: Gelechiidae). Neotropical Entomology. 35(5): 671-676.
Polat, B., Ozpinar, A and Şahin, A.K.2016. Studies of selected biological parameters of tomato leaf miner Tuta absoluta (Meyrick), (Lepidoptera: Gelechiidae) under natural conditions. Phytoparasitica. 44: 195-202

Salama, H., Fouda, M., Ismail, I, A., Ebada, I and Shehata, I. 2014. Life table parameters and fluctuations in the population density of the tomato moth Tuta absoluta (Meyrick) (Lepidoptera: Gelechiidae). Current Science. 3(3): 252-259

Sandeep, K.S., Sridhar, V., Sharma, A and Asokan, R. 2017. Report on the occurrence of South American Tomato moth, Tuta absoluta (Meyrick) in Punjab, India as evident from trap catches and molecular diagnosis. Pest Management in Horticultural Ecosystems. 23(1): 89-91.

Sankarganesh, E., Firake, D.M., Sharma, B., Verma, V.K and Behere, G.T. 2017. Invasion of the South American Tomato Pinworm, Tuta absoluta, in northeastern India: a new challenge and biosecurity concerns. Entomologia Generalis. 36(4): 335-345.

Shanmugam, P.S., Ramaraju, $\mathrm{K}$ and Indhumathi, K. 2016. First record of South American tomato moth, Tuta absoluta (Meyrick) (Lepidoptera: Gelechiidae) in Tamil Nadu, India. Entomon. 41(1): 61-66.

Sharma P.L and Gavkare, O. 2017. New distributional record of invasive pest Tuta absoluta (Meyrick) in NorthWestern Himalayan Region of India. National Academy Science Letter, Springer.

Shasank, P.R., Chandrasekhar, K., Meshram, N.M and Sreedevi, K. 2015. Occurrence of Tuta absoluta (Lepidoptera: Gelechiidae) an invasive pest in India. Indian Journal of Entomology. 77(4): 323-329. 
Shashank, P. R., Suroshe, S.S., Singh, P.K., Chandrashekar, K., Nebapure, S.M and Meshram, N.M. 2016. Report of invasive tomato leaf miner, Tuta absoluta (Lepidoptera: Gelechiidae) from northern India. Indian Journal of Agricultural Sciences. 86(12): 16351636.

Shehata, I., Ebada, I., Ismail, I.A., Fouda, M and Salama, H.S. 2016. On the population dynamics of the tomato leaf miner, Tuta absoluta (Meyrick) (Lepidoptera: Gelechiidae) in Egypt. Ecologia Balkanica.8 (2): 65-75

Simala, M., Milek, T. M and Gabrijel, S. 2011. The results of the monitoring of South American tomato moth, Tuta absoluta (Povolny) (Lepidoptera: Gelechiidae) in Croatia. 25: 293-297

Sridhar, V., Chakravarthy, A. K., Asokan, R., Vinesh, L.S., Rebijith, K.B and Vennila, S. 2014. New record of the invasive
South American tomato leaf miner, Tuta absoluta (Meyrick) (Lepidoptera: Gelechiidae) in India. Pest Management in Horticultural Ecosystems. 20(2): 148-154.

Swathi, P., Swathi, B., Das, S.B., Sridhar, V., Giribabu, O., Snehalatha, G and Neelesh, R. 2017. First report of South American tomato leaf miner, Tuta absoluta (Meyrick) from Madhya Pradesh, India. Pest Management in Horticultural Ecosystems. 23(1): 92-93.

Torres, J., Faria, C.A., Evangeliste, W.S and Pratissoli, D. 2001.Within-plant distribution of the leaf miner Tuta absoluta (Meyrick) immature in processing, with notes on plant phenology. International Journal of Pest Management. 47(3): 173-178.

www.indiastat.com. State-wise area, production and productivity of tomato in India. 2016-17.

\section{How to cite this article:}

Abdul Rasheed, V., S.R. Koteswara Rao, T. Ramesh Babu, T. Murali Krishna, B.V. Bhaskara Reddy and Mohan Naidu, G. 2018. Biology and Morphometrics of Tomato Pinworm, Tuta absoluta (Meyrick) on Tomato. Int.J.Curr.Microbiol.App.Sci. 7(11): 3191-3200. doi: https://doi.org/10.20546/ijcmas.2018.711.367 